\title{
Picnogram: Game of Logic and Mathematics for Dementia Patients
}

\section{Vinothini Kasinathan ${ }^{1}$, Aida Mustapha², Nur Sarah Adha Adam³, Akansha Mandhana ${ }^{4}$}

'School of Computing, Asia Pacific University of Technology and lnnovation, Kuala Lumpur, Malaysia; ${ }^{2}$ Faculty of Computer Science and Information System, Universiti Tun Hussein Onn Malaysia, Batu Pahat, Johor, Malaysia.

\section{ABSTRACT}

Dementia research has shown that there is no definite cure for this disease. It is also known that increased levels of brain activity would evade chances of getting a patient in worse conditions. This study proposes an Android-based mobile game that is designed to increase brain activities among the users especially the dementia patients, as this game involves logic, mathematics and problem-solving skills. In addition to strategizing for the gameplay and the aesthetical attribute of the gaming application called Gamentia, the underlying challenge would be how to engage senior citizens or older adults with no prior experience in using computer or mobile device.

Key Words: Dementia, Mobile, Bran cells, Logic, RAD, Gameplay

\section{INTRODUCTION}

Dementia is a general term for the decline in mental agility and ability that is severe enough to interfere with the patient's daily life. One example of dementia would be memory loss. The most popular causes of dementia are Alzheimer's disease, vascular disorders, Parkinson's disease, Huntington's disease, long-time alcohol or drug use as well as a build-up of fluid in the brain. ${ }^{1}$

In 2015, official death certifications in the United States recorded 110,561 deaths from Alzheimer's Disease alone, making it the sixth leading cause of death in the afore-mentioned country, and the fifth leading cause of death in Americans above the age of sixty-five. ${ }^{2}$ Total payments for healthcare, long-term care and hospice care for people above the age of sixty-five with dementia are estimated to be two hundred and seventy-seven billion USD. This is a statistic with truly gruesome and horrific results. ${ }^{3}$

This project proposes an Android-based mobile game that is designed to increase brain activities among the users, as this game involves logic, mathematics and problem-solving skills. Apart from the logical gameplay, the application should install fun and knowledge into the user. Older adults or dementia patients can get their brain gears activated. ${ }^{4}$
Brain cells get to be stimulated and the overall allure of this game would be the thinking part of it, where the user has to create their tactic and logic to solve the puzzle.

In the present reviewe, we presents the development methodology of the proposed application including the design until the user interface and the evaluation of the proposed application.

\section{MATERIALS AND METHODS}

This project proposed an Android application called Picnogram that is designed to assist mental health for the elderly as well as patients suffering from Dementia. The application is developed based on the Rapid Application Development (RAD) methodology as shown in Figure 1.

Based on the figure, the first step to developing Picnogram is the requirements planning, where requirements can be determined for the success of this mobile game for people of all ages, specifically senior adults. The next step would be user design, which would entail activities such as designing the colours, structure, level, menu and items of the game, making it appeal and be aesthetically pleasing to the eyes of prospective users of this mobile game. Figure 2 shows the

\section{Corresponding Author:}

Vinothini Kasinathan, School of Computing, Asia Pacific University of Technology and Innovation, Kuala Lumpur-57000, Malaysia. Email: vinothini@apu.edu.my

ISSN: 2231-2196 (Print)

Received: 12.08 .2020
ISSN: 0975-5241 (Online)

Revised: 27.09 .2020
Accepted: 24.10 .2020 
use case diagram to develop Picnogram. Prototypes will be tested and improved with every iteration.

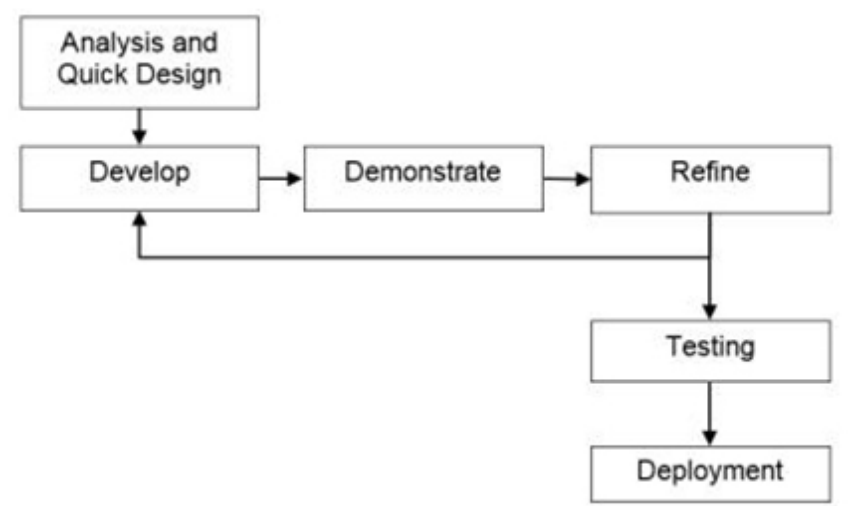

Figure 1: RAD methodology for Picnogram.

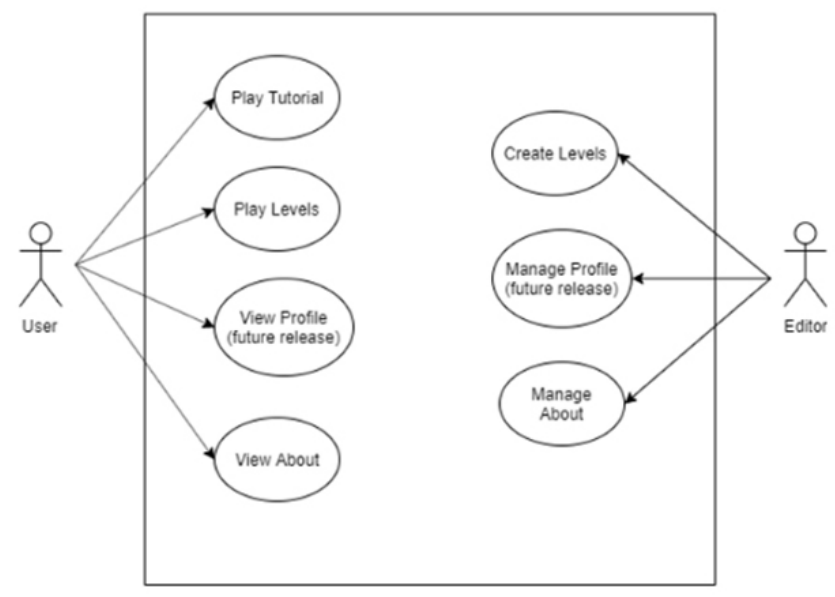

Figure 2: A use case diagram for Picnogram.

The third step consists of the construction aspect of the project. The coding of the game becomes the journey towards completion and success. Fixing bugs, problems and anything in regards to the game's logical and mathematical aspects as well as user interactivity of the game. Users who test this game during the beta state will be able to offer advice and recommendations on how to improve the game. Last, but not least, is the fourth step, which is the cutover. From the beta system, the final product will take its place after several hours of testing, improving and fixing of bugs that might be in the code, untouched.

\section{Development Environment}

Picnogram is developed using the $\mathrm{C} \#$ programming language in GameMaker Studio 2, where the GameMaker Language (GML) is C\#. GameMaker Studio 2 is an Integrated Development Environment (IDE). GameMaker is an Integrated
Development Environment for game-making that is widely used in secondary schools of the United Kingdom. ${ }^{5}$

GameMaker truly supports the learning of basic programming concepts and principles of simple game development. Among the advantages of GameMaker is that it is really good for two-dimensional games, gives users some flexibility with scripting and they can use it for fast prototyping as well. GameMaker Studio 2 is the optimal engine for the development of Picnogram because it does not require three-dimensional game development.

The Operating System (OS) used will be the Android OS. The smartphone market share for Android is reported to be $83.84 \%$, which we can assume that majority of mobile device users have Android. When it comes to Android, it mainly belongs to Google's open and free software stack that includes an operating system, middleware as well as key applications for use on mobile devices. At the time of documentation, the most recent update for the developer's OnePlus mobile device is Android 9.0 Pie. ${ }^{6}$

\section{User Interface}

The main user interface of Picnogram is shown in Figure 3. In the menu, there are Tutorial, Level 1, Level 2, Level 3, About and Exit. Following, on the left screen, is a sprite personally made to make Picnogram look like a fun and aesthetic game.?

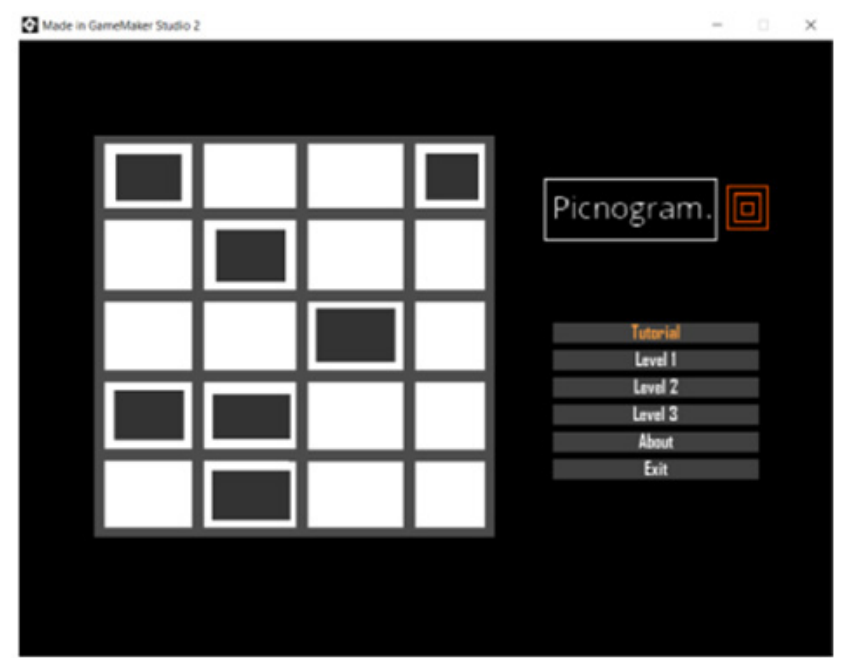

Figure 3: The main user interface of Picnogram.

Figure 4 shows the Tutorial level, where a simple puzzle is shown for the user to try out. This puzzle is considered an easy one, with quite a several columns having an all-ten fill-in of boxes, as well as a single column which does not require a fill-in at all. 


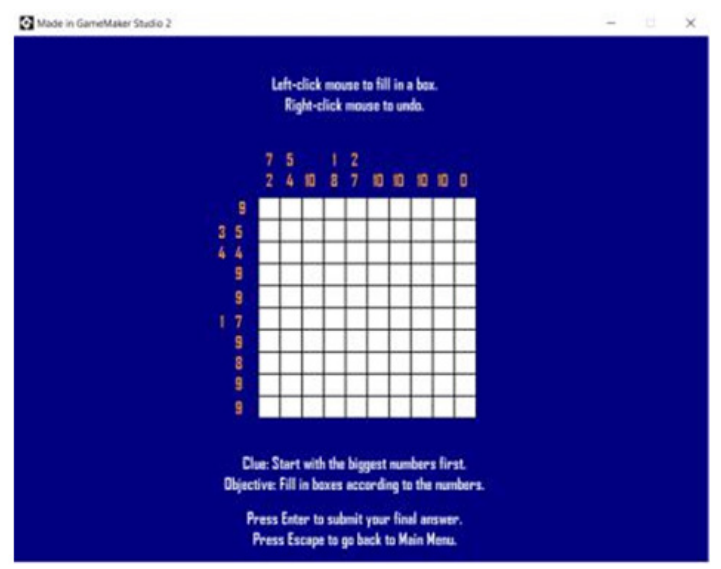

Figure 4: Tutorial page of Picnogram.

Next, the interface of the main gameplay of Picnogram is shown in Figure 5. In the interface, the title gives a clue to the result of the puzzle, upon completion. At the bottom of the screen, the clue and objective are shown. The user would need to press Enter to submit their answer or press the Escape button to go back to the Main Menu.

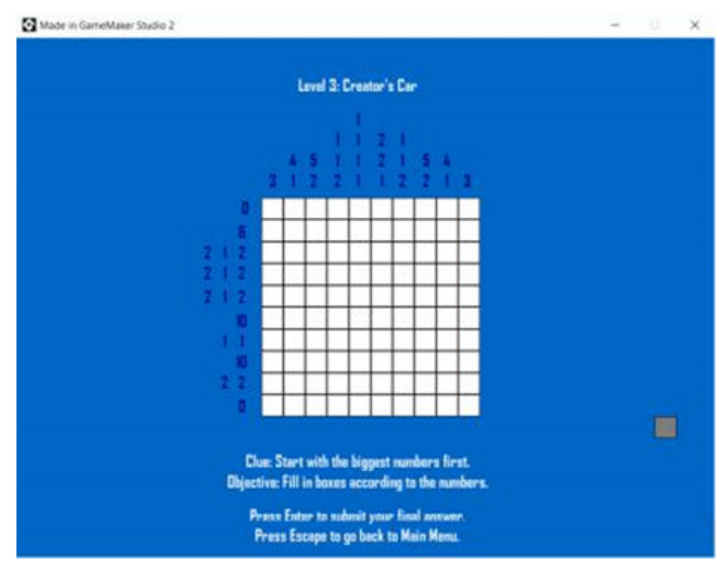

Figure 5: Level 3 of Picnogram.

Once the user submits the answer, one of two things will happen. First, if the answer is correct, Picnogram will bring user to the next level as shown in Figure 6. Second, if the answer is wrong, Picnogram will show the interface as shown in Figure 7.

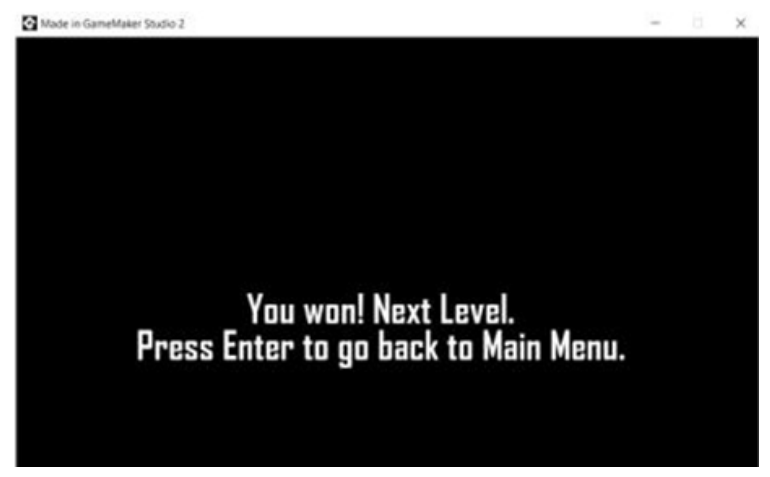

Figure 6: Proceed to next level in Picnogram.

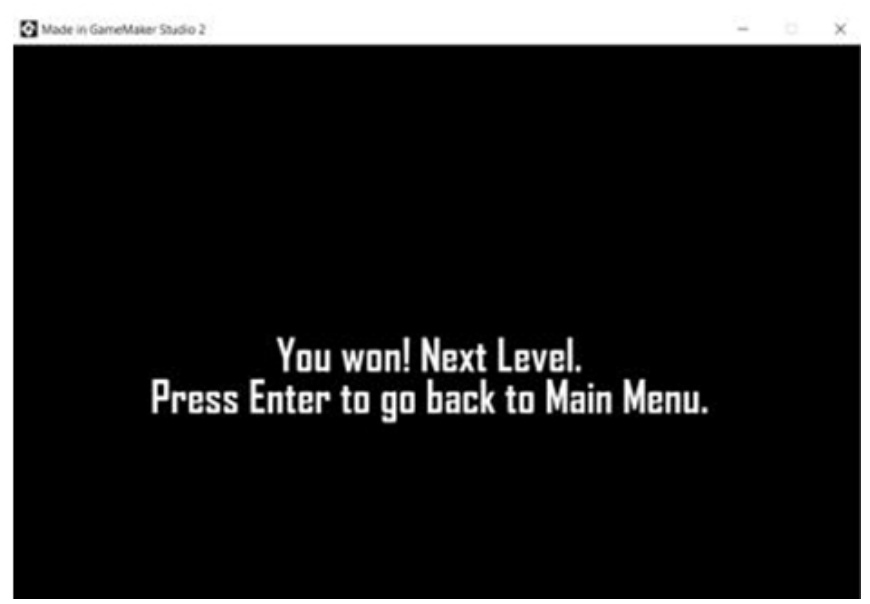

Figure 7: Try again Picnogram.

\section{EVALUATION}

To evaluate the proposed game application for Dementia patients, a survey was carried out via a questionnaire survey for the general public including doctors, but not the patients themselves. The questionnaire has three sections and was distributed via Google Forms and 52 responses were collected. Section A deals with getting to know the respondents that have been invited to fill out the questionnaire (demographic information) and Section B evaluates the experience of playing Picnogram.

\section{Section A}

Section A reports on the demographic information. From a total of 52 respondents, $55.8 \%$ are male. $69.2 \%$ of the respondents are in the age group ranging from sixty to seventy. On the nationality, $67.3 \%$ of respondents are Malaysian, 25\% of respondents are Singaporean and the balance is Mauritian, Pakistani, Sri Lankan, and Syrian. 55.8\% of respondents are living alone and single. $69.2 \%$ are not working but 100 of the respondents responded that they have a mobile device. This is an excellent response to prove the point mobile device has become a necessity for people in the present world. Finally, $63.5 \%$ of respondents use the Android Operating System, while the rest uses iOS for Apple. In the questionnaire, there was an option to state another type of Operating System the user might have, but none of them chose that option.

\section{Section B}

Section B deals with thoughts on Picnogram. Based on a Likert- Scale of one to five, with one being strongly disagreed and five being strongly agreed, respondents will answer with how they feel about the statements provided. The questions start with whether they like to play Picnogram when they have nothing to do as well as if they can play mobile games for hours if the game is fun and entertaining. The results are presented in Figure 8 and 9. 


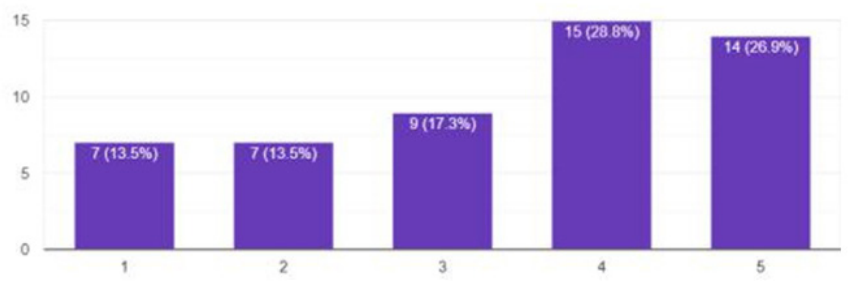

Figure 8: Results of playing Picnogram when boredom strikes.

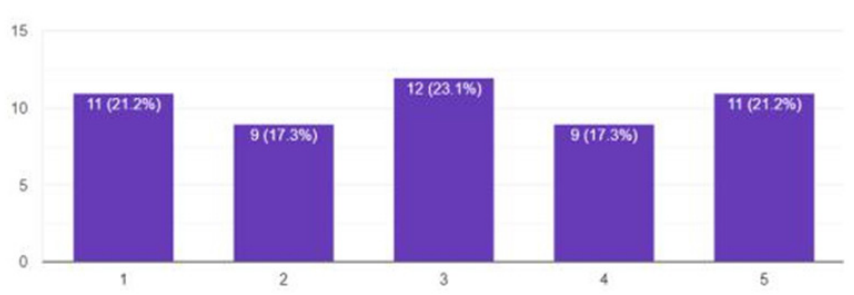

Figure 9: Results of playing Picnogram for hours if it is fun.

Next, the respondents are asked if Picnogram increases thinking and problem-solving skills in general. They are also asked if playing Picnogram in free time is better than using social media, which plays a very important role in filling up time for teens and adults, especially. The respondents are also asked if playing Picnogram can make them feel better and less stressed, which is good to find out if the respondents do feel that way. The results are presented in Figure 10, 11, and 12 , respectively.

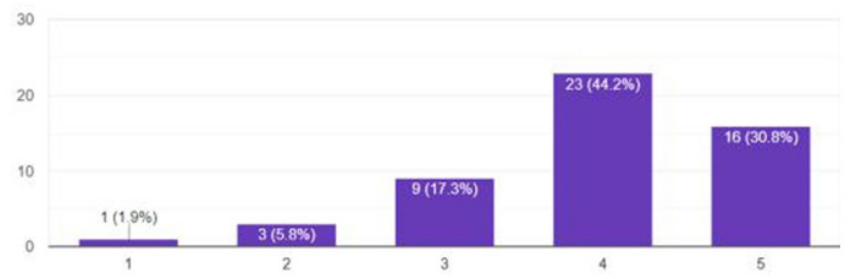

Figure 10: Results of whether educational Picnogram increase thinking and problem-solving skills.

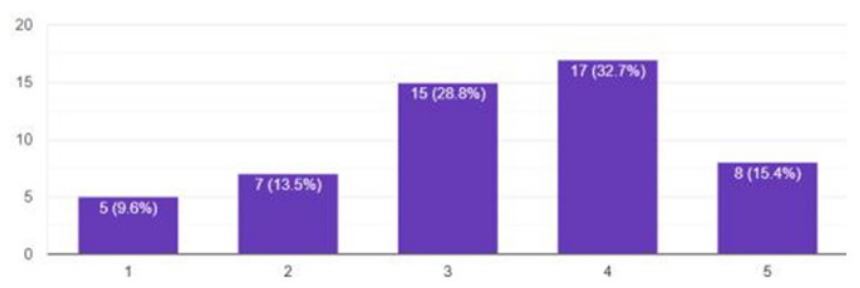

Figure 11: Results of whether playing Picnogram during free time is better than using social media.

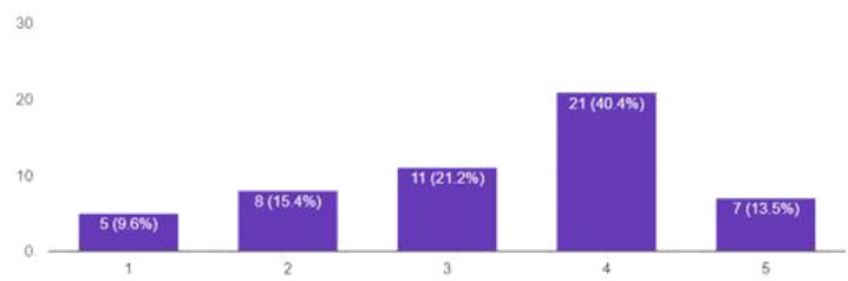

Figure 12: Results of whether playing Picnogram makes the user feel better and less stressed.

Finally, respondents are asked if playing mobile games with mathematics and logic involved is entertaining. This question poses as an indicator of whether the respondents have a liking towards thinking games. The results are presented in Figure 13 and 14.

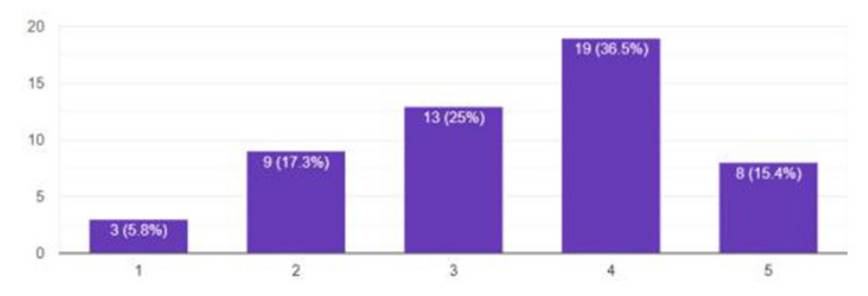

Figure 13: Results of whether playing Picnogram with the mathematics involved is entertaining

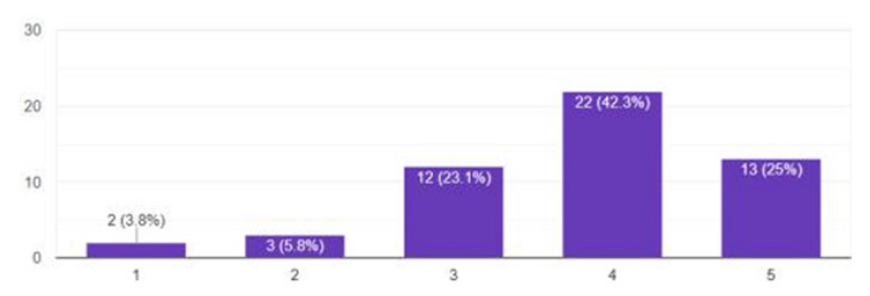

Figure 14: Results of whether playing Picnogram with logic involved is entertaining

This evaluation is very important in evaluating Picnogram. With the responses given above, it is hoped that Picnogram will be viable and feasible in helping the public to increase their mental health.

\section{CONCLUSIONS}

This paper reported an Android-based game application called Picnogram that helps users especially the dementia patients to use their brainpower to increase the activity in their mind to stay alert and lowering risks of having Alzheimer's disease. From the evaluation, Picnogram is found to help adults to engage in a game that increases their mental health through mathematics and problem-solving games. This, in turn, is hoped to help early stages of Alzheimer 
patients to increase brain activity and reduce risks related to the worsening of their condition.

\section{ACKNOWLEDGEMENTS}

The authors also wish to express gratitude to the management of Asia Pacific University of Technology \& Innovation (APU) for their support.

Conflict of Interest: The authors involved in the current study does not declare any competing conflict of interest.

Funding and Sponsorship: No fund or sponsorship in any form was obtained from any organization for carrying out this research work.

\section{REFERENCES}

1. National collaborating Center for Mental Health (UK et al., "Dementia," in Dementia: A NICE-SCIE Guideline on Supporting People With Dementia and Their Carers in Health and Social Care. British Psychological Society, 2007.

2. Alzheimer's Association. Alzheimer's disease facts and figures. Alzheimer's \& Dementia 2018; 367-429.

3. Baldwin BD. Narrative citizenship and dementia: The personal and the political. J Aging Studies 2008; 22(3): 222-228.

4. McShane R, Westby RJ, Roberts E, Minakaran L, Schneider P. Memantine for dementia. Cochrane Database Syste Rev 2019;3: 127-9.

5. Johnson C. Learning to program with game maker. Int J Comp Sci Edu School 2017;1(2): 231-4.

6. Jansen M, Nokia has just updated the budget Nokia 3 to android 9.0 pie. https://www.digitaltrends.com/mobile/android-p-whendo-you-get-it/, 2019.

7. Tyers B. Sprites- in Practical GameMaker: Studio. Springer, 2016;55-63. 